\title{
BMJ Open Assessment of the quality and content of national and international guidelines on hypertensive disorders of pregnancy using the AGREE II instrument
}

\author{
Alessandra N Bazzano, ${ }^{1}$ Erik Green, ${ }^{2}$ Anita Madison, ${ }^{2}$ Andrew Barton, ${ }^{2}$ \\ Veronica Gillispie, ${ }^{3}$ Lydia A L Bazzano ${ }^{2}$
}

To cite: Bazzano AN Green E, Madison A, et al. Assessment of the quality and content of national and international guidelines on hypertensive disorders of pregnancy using the AGREE II instrument. BMJ Open 2016;6:e009189.

doi:10.1136/bmjopen-2015009189

- Prepublication history and additional material is available. To view please visit the journal (http://dx.doi.org/ 10.1136/bmjopen-2015009189).

Received 6 July 2015 Revised 24 November 2015 Accepted 27 November 2015

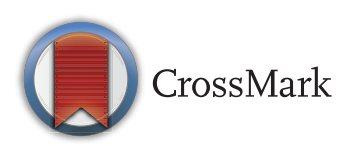

${ }^{1}$ Department of Global Community Health and Behavioral Sciences, Tulane University School of Public Health and Tropical Medicine, New Orleans, Louisiana, USA ${ }^{2}$ Department of

Epidemiology, Tulane University School of Public Health and Tropical Medicine, New Orleans, Louisiana, USA

${ }^{3}$ Ochsner Clinic Foundation, New Orleans, Louisiana, USA

Correspondence to Dr Alessandra N Bazzano; abazzano@tulane.edu

\section{ABSTRACT}

Objectives: High-quality evidence-based clinical practice guidelines can guide diagnosis and treatment to optimise outcomes. The purpose of this study was to evaluate the quality and content of national and international guidelines on hypertensive disorders of pregnancy. Data Sources: The MEDLINE database, the National Guideline Clearinghouse and several international databases were searched for appropriate guidelines from the past 10 years. Study Appraisal and Synthesis Methods: Six guidelines met inclusion and exclusion criteria and were evaluated using the Appraisal of Guidelines for Research and Evaluation II (AGREE II) instrument.

Results: A total of 695 records were identified and screened by two authors. Disorder definitions, classifications, preventive measures and treatment recommendations were evaluated and compared among guidelines. AGREE II results varied widely across domains and categories. Only two guidelines received consistently high ratings across domains and few demonstrated a high level of methodological rigour. Recommendations regarding classification and treatment were similar across guidelines, while assessment of preventive measures varied widely.

Conclusions: Clinical practice guidelines for hypertensive disorders of pregnancy vary significantly in quality and with respect to assessment of preventive measures.

\section{INTRODUCTION}

Hypertensive disorders of pregnancy (HDP) pose a significant public health problem within the USA and internationally. They are a major cause of maternal and perinatal morbidity and mortality accounting for nearly $18 \%$ of all maternal deaths worldwide, with an estimated 62 000-77 000 deaths per year. ${ }^{1}$ Pre-eclampsia has been identified as the leading reason for admission to the intensive care unit in the puerperal period. ${ }^{2}$ Five to $10 \%$ of pregnancies in the USA are affected

\section{Strengths and limitations of this study}

- Evaluation of each guidelines by five raters.

- Comprehensive search strategy with the use of multiple databases.

- Use of a structured, validated tool.

- Inclusion of only English language guidelines. This may result in the exclusion guidelines designed for use in non-English speaking countries.

- Differences between raters were not assessed. However, the larger number of raters in our study should improve reliability in the overall ranking of guidelines.

- We chose to focus on guidelines of broader scope which may have resulted in failure to identify guidelines which, though of narrow scope, may have been pertinent to recommendations.

by hypertensive disorders. ${ }^{1}$ In Europe, estimates range between $6 \%$ and $8 \%$, with global estimates as high as $15 \% .^{23}$ In higher income countries, rates of pre-eclampsia, gestational hypertension and chronic hypertension have increased due to the increased number of pregnancies among women of advanced maternal age and the obesity epidemic. While widespread antenatal care and magnesium sulfate use have led to a decrease in the rate of eclampsia, ${ }^{3}$ it remains a significant problem in low-income countries.

HDP include chronic hypertension, gestational hypertension, pre-eclampsia and chronic hypertension with superimposed pre-eclampsia. ${ }^{4}$ Women with pre-eclampsia and eclampsia have a 3-fold to 25-fold increased risk of serious complications such as pulmonary oedema, placental abruption, aspiration pneumonia, renal failure, hepatic failure, disseminated intravascular coagulation and stroke. ${ }^{2}{ }^{3}$ In addition, hypertensive disorders during pregnancy may result in 
long-term effects on the mother and baby. These longterm outcomes include an increased risk for cardiovascular morbidity and mortality, cerebrovascular disease, peripheral artery disease, venous thromboembolism, as well as renal and neurological sequelae. ${ }^{2}{ }^{3}$ In addition, women with pre-eclampsia have an increased risk for developing chronic hypertension. An earlier gestational age of pre-eclampsia onset and delivery in the first pregnancy is associated with an increased risk of recurrent pre-eclampsia in a subsequent pregnancy. ${ }^{25}$

In addition to the maternal effects, there are numerous effects on the fetus and infant. Studies from industrialised countries such as Norway show that women with pre-eclampsia have a $35 \%$ higher risk of stillbirth, while studies from less developed nations show that preeclampsia is associated with a twofold risk of stillbirth. ${ }^{2}$ Women also have an increased risk for iatrogenic preterm delivery which is more likely to result in low birth weight. $^{2}{ }^{6}$ Neonatal mortality is about twofold higher among infants whose mothers have preeclampsia. ${ }^{7}$ Offspring of women with pre-eclampsia are also at increased risk of low APGAR scores, febrile seizures, encephalopathy and neonatal intensive care unit admission. ${ }^{689}$ Long-term health effects for the offspring include higher levels of systolic and diastolic blood pressure (DBP) in childhood and adolescence, increased risks of hospitalisation due to metabolic disorders, epilepsy and other complications. ${ }^{10-12}$ In addition, longterm follow-up studies of offspring have shown increased risks of stroke, and a trend towards increased risk of coronary heart disease, heart failure, kidney disease and diabetes mellitus in later life. ${ }^{13} 14$

Guidelines should promote best practices in the management of hypertensive disorders in pregnancy with the expected health benefits of the reduction of prenatal and perinatal morbidity and mortality in women with, or at risk of developing, hypertension in pregnancy, as well as reduction of infant morbidity and mortality associated with these hypertensive disorders.

In light of the high burden of maternal and perinatal morbidity and mortality, providers and policymakers require accurate and timely guidance for the management of hypertensive disorders in pregnancy. A number of guidelines have been published and disseminated with an emphasis on clinical guidance. The aim of the current review was to identify quality and concordance of guidelines from national and international sources to improve the quality of healthcare by promoting systematic development of clinical practice and for informing areas of future research.

\section{METHODS}

To assess guideline quality and concordance, we initiated a comprehensive guideline review. Study steps comprised a comprehensive guideline search, formulation and application of selection criteria, assessment of guideline quality, compilation of results and analysis.
Guideline sources and selection

Several databases were searched from 1 May to 31 May, 2014 for guidelines published in the past 10 years pertaining to the topic of hypertension in pregnancy. Sources and databases included in the search consisted of Medline, the National Guideline Clearinghouse, ${ }^{15}$ Guidelines International Network Web site, ${ }^{16}$ National Institute Health and Care Excellence Web site, ${ }^{17}$ Canadian Medical Association (CMA Infobase) Web site ${ }^{18}$ Australian Government National Health and Medical Research Council (Clinical Practice Guidelines Portal Web site) ${ }^{19}$ Australian Government National Health and Medical Research Council (Clinical Practice Guidelines Search Web site), ${ }^{20}$ Scottish Intercollegiate Guidelines Network Web site, ${ }^{21}$ New Zealand Ministry of Health (New Zealand Guidelines Group Web site), ${ }^{22}$ Agency for Quality in Medicine (AQuMed Database Web site) ${ }^{23}$ National Disease Management Guidelines Programme (German Disease Management Guidelines), ${ }^{24}$ British Columbia Ministry of Healthm (BCGuidelines Web site). ${ }^{25}$

Terms searched included pregnancy, hypertension, pregnancy hypertension, hypertension management, alone and in conjunction with guideline and guidelines. We also performed a manual search of references cited in the published guidelines and relevant review articles. The full search strategy is outlined in online supplementary appendix 1.

The search results were selected for further review on the basis of several criteria. Two researchers screened the full-text articles of retrieved hits. Resulting documents were not selected if they were not a guideline or if their scope did not include HDP.

Since we sought to assess the management of hypertension in pregnancy in general, guidelines were removed if they were limited to specific populations or if their scope was focused on specific conditions (eg, guideline covered pre-eclampsia only). Guidelines were only included if they were published less than 10 years prior, if they were in English, and if they were not primarily or entirely derived from other guidelines.

\section{Quality assessment}

To objectively assess guideline quality, we used the Appraisal of Guidelines for Research \& Evaluation (AGREE II) instrument. The AGREE II instrument consists of 23 items organised into six domains. Reviewers assessed each item and assigned a score from 1 (strongly disagree) to 7 (strongly agree). Overall quality of the guideline (1-7) and recommendation were also assessed. Final domain scores $(0-100 \%)$ were calculated based on the sum of ratings across all reviewers and scaled to include the maximum possible score as well as the difference between the maximum and minimum possible scores for that domain. ${ }^{26}$ Five appraisers (including ANB, LALB, EG, AM, AB) independently scored the guidelines using the AGREE II system. 


\section{RESULTS}

Figure 1 presents a flow diagram outlining the results of the assessment and review. A total of six guidelines met the selection criteria. These guidelines came from various national and international sources and were not identical in scope or recommendation for clinical practice. Four clinical practice guidelines (CPGs) were national guidelines. These were from the USA (American College of Obstetrics and Gynecology; ACOG), ${ }^{27}$ Canada (SOGC), UK (NICE) and Australia (QLD). Two CPGs originated from multinational organisations: the Society of Obstetric Medicine of Australia and New Zealand (SOMANZ) and European Society of Cardiology (ESC). One document specifically covered management of all cardiovascular diseases during pregnancy, while the others were more focused, covering the

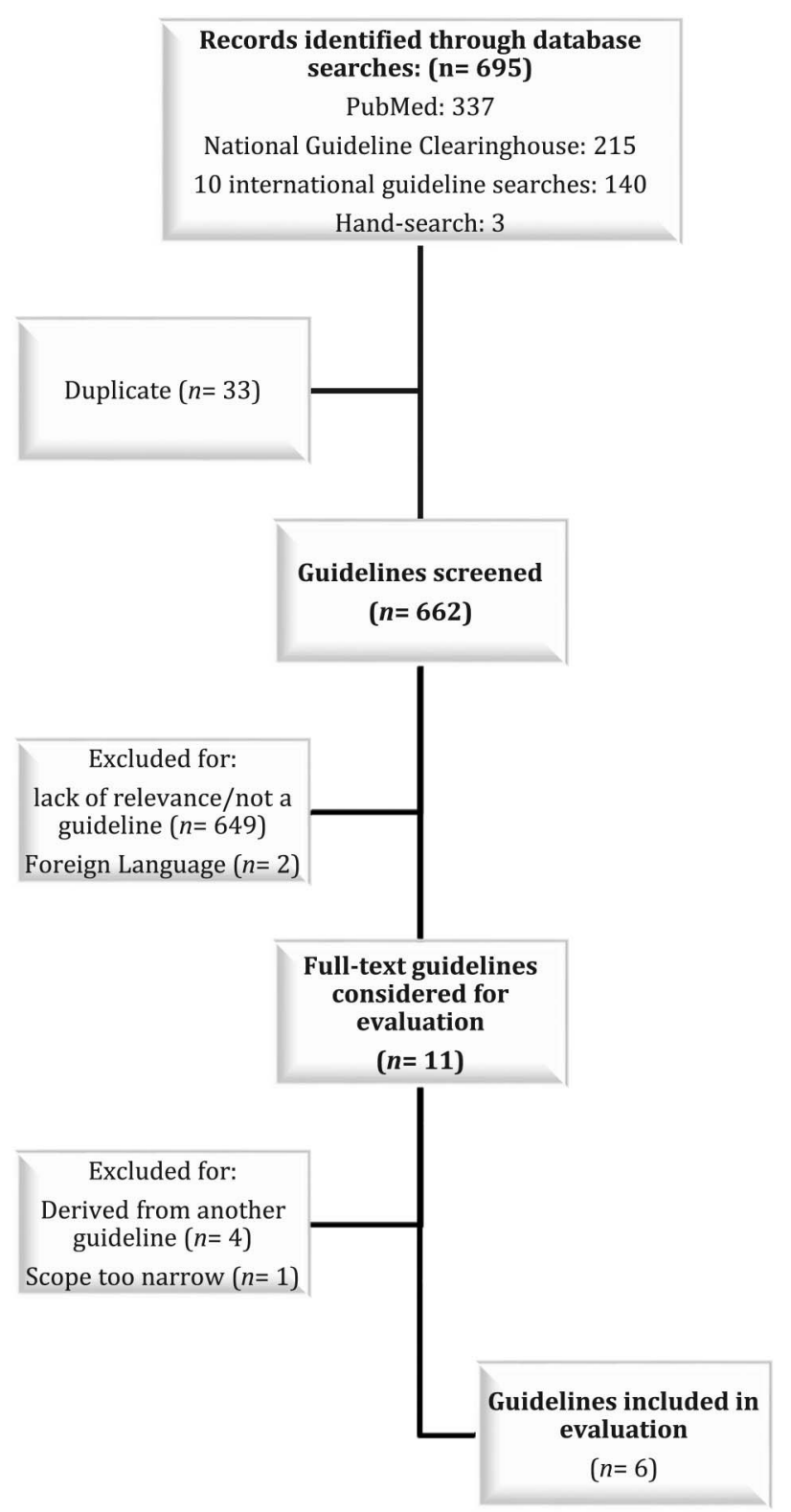

Figure 1 Flow diagram outlining the guideline selection process. management of chronic hypertension, gestational hypertension, pre-eclampsia or eclampsia. All five appraisers said that they would recommend use of the National Institute of Health and Care Excellence (NICE) guideline. Four of the five appraisers recommended use of the SOGC guideline with the fifth appraiser giving no response. The other four guidelines received varied reviewer responses on recommendation for use.

\section{Appraisal of guidelines and consensus statements}

Table 1 shows the standardised domain scores for each guideline for each of the six quality domains assessed with the AGREE II tool. The overall quality of reporting of the guideline development process, as assessed by the AGREE method, varied widely between CPGs. The domain 'scope and purpose' scores ranged from $42 \%$ to $98 \%$. NICE and SOGC received the highest score in that domain at $98 \%$, with ESC scoring the lowest at $42 \%$. For the domain 'stakeholder involvement' scores ranged from 30-93\%, with the highest being SOGC and the lowest SOMANZ. Scores on 'rigour of development' ranged from $24 \%$ to $91 \%$. In contrast, 'clarity of presentation' ranged from $63 \%$ to $94 \%$. In the domain 'applicability', scores ranged from $32 \%$ to $76 \%$ and in 'editorial independence', scores ranged widely from $7 \%$ to $70 \%$ (7\% SOMANZ). Across all domains, NICE and SOGC received the highest scores.

\section{Classification of hypertension}

Table 2 illustrates variations in classification of hypertension by CPG. Hypertension occurring after 20 weeks gestation and resolving 12 weeks postpartum in the absence of maternal or fetal features of pre-eclampsia was defined as gestational hypertension by all guidelines.

All CPGs defined chronic (pre-existing) hypertension as a systolic BP $(\mathrm{SBP}) \geq 140 \mathrm{~mm} \mathrm{Hg}$ or DBP $\geq 90 \mathrm{~mm} \mathrm{Hg}$ that is diagnosed before pregnancy or before 20 weeks gestation. In addition, chronic hypertension was defined as hypertension found after 20 weeks gestation and persisting 12 weeks postpartum according to five of the six guidelines. However, ESC stated that diagnosis of chronic hypertension would occur at $>42$ days postpartum.

Severe hypertension was defined as BP $\geq 160$ / $110 \mathrm{~mm} \mathrm{Hg}(\mathrm{N}=5)$ in the majority of the CPGs, but as $\geq 170 / 110 \mathrm{~mm} \mathrm{Hg}(\mathrm{N}=1)$ in SOMANZ.

Pre-eclampsia was defined as a multisystem syndrome characterised by hypertension and involving one or more other organ systems and/or the fetus (SOMAZ, SOGC, ACOG, ESC, QLD). These organ systems include renal, hematological, hepatic, neurological or pulmonary. Fetoplacental complications which are considered criteria necessary to make the diagnosis of pre-eclampsia included fetal growth restriction/IUGR (SOMANZ, SOGC, ESC, QLD), abnormal fetal heart rate (SOGC), oligohydramnios (SOGC), absent or reversed enddiastolic flow by Doppler velocimetry (SOGC) and placental abruption (QLD, SOGC and SOMANZ). 
Table 1 Clinical practice guideline domain scores using the AGREE-II instrument

\begin{tabular}{lllllll}
\hline Domain & SOMANZ (\%) & ACOG (\%) & ESC (\%) & QLD (\%) & NICE (\%) & SOGC (\%) \\
\hline Scope and purpose & 46 & 70 & 42 & 74 & 98 & 98 \\
Stakeholder involvement & 30 & 61 & 34 & 74 & 93 & 91 \\
Rigour of development & 24 & 43 & 55 & 60 & 91 & 74 \\
Clarity of presentation & 63 & 88 & 91 & 87 & 94 & 93 \\
Applicability & 32 & 51 & 41 & 39 & 73 & 76 \\
Editorial independence & 7 & 55 & 65 & 48 & 62 & 70 \\
\hline
\end{tabular}

AGREE-II, Appraisal of Guidelines for Research and Evaluation II; ESC, European Society of Cardiology; NICE, National Institute of Health and Care Excellence; QLD, Queensland (Australia); SOMANZ, Society of Obstetric Medicine of Australia and New Zealand.

Proteinuria was defined as $\geq 0.3 \mathrm{~g} /$ day in a complete $24 \mathrm{~h}$ urine collection or $\geq 30 \mathrm{mg} / \mathrm{mmol}$ urinary creatinine in a spot (random) urine sample by all CPGs and should be suspected if urine dipstick is $\geq+1$ among certain guidelines (SOMANZ, SOGC, ACOG, NICE). Urine dipstick testing should be done for proteinuria and quantification by laboratory methods if greater than or equal to 2+ (QLD). Proteinuria was not considered mandatory for diagnosis by $5 / 6$ guidelines.

Severe pre-eclampsia was defined as systolic BP of $160 \mathrm{~mm} \mathrm{Hg}$ or higher or DBP of $110 \mathrm{~mm} \mathrm{Hg}$ or higher on two occasions at least $4 \mathrm{~h}$ apart while the patient is on bed rest; thrombocytopaenia; impaired liver function; progressive renal insufficiency; pulmonary oedema; or new onset cerebral or visual disturbances, according to ACOG and SOGC. ESC mentioned only the signs and symptoms of severe pre-eclampsia without mention of $\mathrm{BP}$ range. NICE defined severe pre-eclampsia as pre-eclampsia with severe hypertension and/or with symptoms, and/or biochemical and/or hematological impairment. Other CPG definitions of severe pre-eclampsia overlap with the definitions for pre-eclampsia without severe features.

Chronic hypertension with superimposed preeclampsia was defined by four guidelines (SOGC, SOMANZ, ESC, Queensland (Australia)) as chronic hypertension (after 20 weeks gestation) in the setting of new-onset worsening of BPs, proteinuria, thrombocytopenia, or other systemic complications. ACOG defined it as chronic hypertension in association with pre-eclampsia.

\section{Table 2 Classification of hypertension by CPGs}

\begin{tabular}{|c|c|c|c|c|c|c|}
\hline \multirow[b]{2}{*}{ Classification of hypertension } & \multicolumn{6}{|l|}{ CPGs } \\
\hline & SOMANZ & ACOG & ESC & QLD & NICE & SOGC \\
\hline \multicolumn{7}{|l|}{ Chronic hypertension } \\
\hline Persists past 12 weeks & $\mathrm{x}$ & $\mathrm{X}$ & & $\mathrm{x}$ & $\mathrm{x}$ & $\mathrm{x}$ \\
\hline Persists past 42 days & & & $\mathrm{x}$ & & & \\
\hline \multicolumn{7}{|l|}{ Severe hypertension } \\
\hline $170 / 110$ & $\mathrm{x}$ & & & & & \\
\hline $160 / 110$ & & $\mathrm{x}$ & $\mathrm{x}$ & $\mathrm{x}$ & $\mathrm{x}$ & $\mathrm{x}$ \\
\hline White coat hypertension & $x$ & & & $x$ & & $\mathrm{x}$ \\
\hline Masked hypertension & & & & & & $\mathrm{x}$ \\
\hline Gestational hypertension & $\mathrm{x}$ & $x$ & $\mathrm{x}$ & $x$ & $\mathrm{x}$ & $x$ \\
\hline \multicolumn{7}{|l|}{ Pre-eclampsia } \\
\hline Hypertension after 20 weeks & $\mathrm{x}$ & $x$ & $\mathrm{x}$ & $x$ & $\mathrm{x}$ & $\mathrm{x}$ \\
\hline Proteinuria & $x$ & $\mathrm{x}$ & $\mathrm{x}$ & $x$ & $\mathrm{x}$ & $\mathrm{X}$ \\
\hline Liver dysfunction & $x$ & $x$ & $\mathrm{x}$ & $\mathrm{x}$ & & $\mathrm{x}$ \\
\hline \multicolumn{7}{|l|}{ Renal dysfunction } \\
\hline Hematological dysfunction & $\mathrm{x}$ & $x$ & & $x$ & & $\mathrm{x}$ \\
\hline Pulmonary oedema & $\mathrm{x}$ & $\mathrm{x}$ & & $x$ & $\mathrm{x}$ & $\mathrm{x}$ \\
\hline Visual, neurological or cerebral disturbances & $x$ & $x$ & & $\mathrm{x}$ & & $x$ \\
\hline Fetal growth restriction & $\mathrm{x}$ & $\mathrm{x}$ & $\mathrm{x}$ & $x$ & & $x$ \\
\hline Oligohydramnios & $x$ & $x$ & & $x$ & & $x$ \\
\hline Placental abruption & & & & & & $x$ \\
\hline Absent or reversed end-dystolic flow & $x$ & & & $x$ & & $x$ \\
\hline Abnormal fetal heart rate & & & & & & $x$ \\
\hline Superimposed pre-eclampsia & $x$ & $x$ & $\mathrm{x}$ & $x$ & & $x$ \\
\hline Eclampsia & $x$ & $x$ & & $x$ & $\mathrm{x}$ & $x$ \\
\hline HELLP syndrome & $\mathrm{x}$ & $\mathrm{x}$ & $\mathrm{x}$ & $\mathrm{x}$ & $\mathrm{x}$ & $\mathrm{x}$ \\
\hline
\end{tabular}


Hemolysis, Elevated Liver enzymes, Low Platelet count (HELLP) syndrome was defined in all six CPGs as haemolysis, elevated liver enzymes and low platelet count.

According to SOMANZ, NICE, SOGC and QLD, eclampsia was defined as the occurrence of one or more seizures (convulsions) in association with pre-eclampsia. ACOG defined eclampsia as the presence of new onset grand mal seizures in a woman with pre-eclampsia, which can occur before, during, or after labour. ESC lacked a definition for eclampsia.

One guideline, SOGC, defined a transient hypertensive effect as an office SBP $\geq 140 \mathrm{~mm} \mathrm{Hg}$ or a DBP $\geq 90 \mathrm{~mm} \mathrm{Hg}$ that is not confirmed at rest on repeat measurement, on the same or subsequent visits.

White coat hypertension was defined in three CPGs (QLD, SOGC and SOMANZ) as hypertension in a clinical setting with normal $\mathrm{BP}$ in a non-clinical setting when assessed by $24 \mathrm{~h}$ ambulatory BP monitoring or home BP monitoring using an appropriately validated device. One CPG (SOGC) defined a masked hypertensive effect as a BP that is normal in the office but is elevated on ambulatory or home BP monitoring (systolic $\geq 135 \mathrm{~mm} \mathrm{Hg}$ or diastolic $\geq 85 \mathrm{~mm} \mathrm{Hg}$ ).

SOGC recommended that all pregnant women be assessed for proteinuria, while two CPGs (SOMANZ, ACOG) did not recommend that all pregnant women be assessed for proteinuria.

\section{Prevention modalities}

Various prevention modalities were described by the CPGs, including pharmaceutical and alternative options. These are outlined in table 3.

\section{Aspirin}

Low-dose acetylsalicylic acid use for pre-eclampsia prevention in high-risk women was recommended in five of six
CPGs (SOMANZ, ACOG, SOGC, NICE, ESC). However, dosage and timing varied among the guidelines. Dosages ranged from 50 to $162 \mathrm{mg}$ depending on the CPG. Women considered at an increased risk were those who have a personal or family history of HDP, chronic medical disease and/or abnormal uterine artery Doppler before 24 weeks gestation. Recommendations regarding the timing of initiation of aspirin varied by CPG. Most stated therapy should be started early in pregnancy (SOMANZ, SOGC, NICE, ACOG, ESC). Dates ranged from 12 to 20 weeks gestation. Recommendations were also made for administration at bedtime (ESC, SOGC) and continued use until delivery (ESC, NICE, SOGC).

\section{Calcium}

Three CPGs made recommendations about calcium supplementation (ACOG, SOMANZ, SOGC). Recommendations for calcium supplementation were $1.5 \mathrm{~g}$ /day (SOMANZ), or at least $1 \mathrm{~g} /$ day (SOGC, ESC), offered to women at increased risk of pre-eclampsia, particularly in women with a low dietary calcium intake $(<600 \mathrm{mg} /$ day $)$. ACOG noted that calcium supplementation may be useful in populations with low calcium intake but did not make a more specific recommendation.

\section{Vitamin $\mathrm{C}$ and $\mathrm{E}$}

Four CPGs recommend against prophylactic antioxidant therapy with vitamin $\mathrm{C}$ and $\mathrm{E}$ (ACOG, NICE, SOGC, SOMANZ).

\section{Folic acid}

Recommendations varied for the use of folic acid for HDP among CPGs. Two CPGs stated that periconceptual and ongoing use of a folate-containing multivitamin may be useful in preventing pre-eclampsia but that there is

\begin{tabular}{|c|c|c|c|c|c|c|}
\hline \multirow[b]{2}{*}{ Prevention modalities for pre-eclampsia } & \multicolumn{6}{|c|}{ CPGs } \\
\hline & ESC & ACOG & SOMANZ & NICE & QLD & SOGC \\
\hline Aspirin & + & + & + & + & - & + \\
\hline Calcium & + & - & + & & & + \\
\hline Vitamin $\mathrm{C}$ and $\mathrm{E}$ & $\mathrm{X}$ & $\mathrm{X}$ & $x$ & $\mathrm{X}$ & & $\mathrm{X}$ \\
\hline LMWH & & & - & $\mathrm{X}$ & & \\
\hline Fish oil & $x$ & $\mathrm{X}$ & $\mathrm{X}$ & & & \\
\hline Folic acid & & + & - & $\mathrm{X}$ & & - \\
\hline Nitric acid donors & & $\mathrm{X}$ & & & & \\
\hline progesterone & & $x$ & & & & \\
\hline Magnesium & & $x$ & & & & $x$ \\
\hline Zinc & & & & & & $X$ \\
\hline Salt restriction & $x$ & $X$ & & $X$ & & $X$ \\
\hline Caloric restriction & $x$ & & & & & $x$ \\
\hline Thiazide diuretics & & & & & & $\mathrm{X}$ \\
\hline
\end{tabular}


insufficient evidence to recommend for or against folic acid supplements (SOGC and SOMANZ). However, NICE recommended against folic acid for the prevention of pre-eclampsia in pregnancy. ACOG stated that folic acid supplementation should be recommended for the management of women with prior pre-eclampsia. ESC and QLD made no mention of folic acid for prevention of pre-eclampsia.

\section{Low molecular weight heparin}

Recommendations varied for the use of low molecular weight heparin (LMWH) for HDP among CPGs. SOMANZ reported that there is insufficient evidence for or against LMWH. However, NICE recommended against the use of LMWH for the prevention of preeclampsia in pregnancy.

\section{Other therapies}

The six guidelines recommended against various therapies, which included fish oil (NICE, SOMANZ), nitric acid donors (NICE), progesterone (NICE), diuretics (NICE, SOGC), magnesium (NICE, SOGC), garlic (NICE), prostaglandin precursors (SOGC) and zinc (SOGC). Four CPGs made recommendations against dietary salt restriction (SOGC, ACOG, ESC, NICE).

\section{Treatment modalities}

\section{Delivery}

All six CPGs stated that delivery is the only definitive way to terminate hypertensive disorders of pregnancy, but recommendations were provided for management of symptoms. A full description of treatment modalities recommended by CPGs is presented in table 4. All guidelines recommended that women with severe preeclampsia who are unstable or have rapidly deteriorating maternal-fetal conditions, should be delivered regardless of gestational age. Three recommended expectant management for women with stable pre-eclampsia between 24 and 34 weeks gestation (SOGC, NICE and ACOG). However, for women with severe pre-eclampsia at or beyond 34 weeks' gestation, maternal stabilisation followed by delivery was recommended by two guidelines (ACOG, NICE). Women less than 24 weeks gestational age should be counselled about possible delivery within days according to three CPGs (NICE, ACOG, SOGC). For women with pre-eclampsia between $34+0$ and 36 +6 weeks gestation, there were varying recommendations due to insufficient evidence. SOMANZ made no clear recommendation for delivery in a pre-eclamptic woman, other than delivery at 37 weeks or earlier if severe features are present. ESC also made no clear recommendation. For women with gestational hypertension at $\geq 37$ +0 weeks gestation, delivery was recommended in five of six CPGs (SOGC, SOMANZ, ACOG, QLD, NICE).

\section{Bed rest}

Five CPGs recommended against strict bed rest (ACOG, SOGC, NICE, SOMANZ, QLD). One CPG mentioned that for women with gestational hypertension, some bed rest may be useful to decrease severe hypertension and

\begin{tabular}{|c|c|c|c|c|c|c|}
\hline \multirow[b]{2}{*}{ Treatment } & \multicolumn{6}{|l|}{ CPGs } \\
\hline & $\overline{A C O G}$ & ESC & SOMANZ & SOGC & QLD & NICE \\
\hline Bed rest & $x$ & & $x$ & $x$ & $\mathrm{x}$ & $x$ \\
\hline $\begin{array}{l}\text { Antihypertensive } \\
\text { therapy }\end{array}$ & + & + & + & + & + & + \\
\hline $\begin{array}{l}\text { Antenatal } \\
\text { Corticosteroids }\end{array}$ & + & + & + & + & + & + \\
\hline \multicolumn{7}{|l|}{ Magnesium sulfate } \\
\hline For eclampsia & + & + & + & + & + & + \\
\hline $\begin{array}{l}\text { For severe } \\
\text { pre-eclampsia }\end{array}$ & + & & & + & + & + \\
\hline \multicolumn{7}{|l|}{ Timing of delivery } \\
\hline $\begin{array}{l}\text { Gestational } \\
\text { hypertension }\end{array}$ & $\geq 37$ weeks & & $\geq 37$ weeks & $\geq 37$ weeks & $\geq 37$ weeks & $\geq 37$ weeks \\
\hline \multicolumn{7}{|l|}{ Pre-eclampsia } \\
\hline 24 weeks & Counsel & & & Counsel & & Counsel \\
\hline 24-34 weeks & $\begin{array}{l}\text { Managed } \\
\text { expectantly }\end{array}$ & & & $\begin{array}{l}\text { Managed } \\
\text { expectantly }\end{array}$ & & $\begin{array}{l}\text { Managed } \\
\text { expectantly }\end{array}$ \\
\hline 34-36 weeks & Inconclusive & & & Inconclusive & & Inconclusive \\
\hline$\geq 37$ weeks & Deliver & & Deliver & Deliver & Deliver & Deliver \\
\hline $\begin{array}{l}\text { Severe } \\
\text { pre-eclampia }\end{array}$ & $\begin{array}{l}\text { Immediate } \\
\text { delivery }\end{array}$ & $\begin{array}{l}\text { Immediate } \\
\text { delivery }\end{array}$ & $\begin{array}{l}\text { Immediate } \\
\text { delivery }\end{array}$ & $\begin{array}{l}\text { Immediate } \\
\text { delivery }\end{array}$ & $\begin{array}{l}\text { Immediate } \\
\text { delivery }\end{array}$ & $\begin{array}{l}\text { Immediate } \\
\text { delivery }\end{array}$ \\
\hline
\end{tabular}


preterm birth, but strict bed rest should not be prescribed (SOGC). Another CPG reported that it may be harmful (QLD).

\section{Antihypertensives}

Guidelines varied with regard to antihypertensive treatment. Antihypertensive treatment should be started promptly in all women with a SBP of $\geq 170 \mathrm{~mm} \mathrm{Hg}$ (SOMANZ and ESC) or $\geq 160$ (SOGC, ACOG, NICE, QLD) or a DBP $\geq 110 \mathrm{~mm} \mathrm{Hg}$ (SOMANZ, SOGC, ACOG, NICE, ESC) or $>110$ (QLD). Treatment should aim for a gradual and sustained lowering of BP due to risk of intracerebral haemorrhage and eclampsia (SOMANZ). SOGC stated that BP should be lowered to $<160 \mathrm{~mm} \mathrm{Hg}$ systolic and $<110 \mathrm{~mm} \mathrm{Hg}$ diastolic. The NICE guideline suggested a BP goal of $<150 / 100$.

Regarding severely raised BP, all CPGs endorsed labetalol and nifedipine for the initial lowering of BP. Others included hydralazine (SOMANZ, ACOG, SOGC, QLD, NICE), diazoxide (SOMANZ, QLD) and methyldopa (ESC). ESC recommended against using intravenous hydralazine as its use is associated with more prenatal adverse effects than other drugs. SOMANZ also stated that persistent or refractory severe hypertension may require repeated doses of antihypertensives or an intravenous infusion of labetalol $20-160 \mathrm{mg} / \mathrm{h}$ or hydralazine $5-10 \mathrm{mg} / \mathrm{h}$, titrated to BP response. In addition, infusions of sodium nitroprusside (SOMANZ, SOGC, QLD) or glycerol trinitrate (SOMANZ, ESC, QLD) were noted to be effective but not recommended due to toxicity. One guideline recommended that in a hypertensive crisis, sodium nitroprusside should be used in the short term (ESC).

For BPs in the mild and moderate range, recommendations among CPGs varied. For BP less than 160/110, antihypertensive medications were not suggested by ACOG, but SOMANZ and QLD indicated that use of these therapies should still be considered. First-line drugs mentioned by CPGs included methyldopa (NICE) and labetalol (NICE), while second-line drugs mentioned included hydralazine (NICE), nifedipine (NICE) and prazosin (QLD).

ESC recommended SBP of $140 \mathrm{~mm} \mathrm{Hg}$ or a DBP of $90 \mathrm{~mm} \mathrm{Hg}$ as thresholds for antihypertensive treatment in women with gestational hypertension, pre-existing hypertension with the superimposition of gestational hypertension, hypertension with subclinical organ damage or symptoms at any time during pregnancy. In all other circumstances, the ESC threshold was an SBP of $150 \mathrm{~mm} \mathrm{Hg}$ and a DBP of $95 \mathrm{~mm} \mathrm{Hg}$. Above these levels, treatment was mandatory in all CPGs. $\alpha$-Methyldopa was considered the drug of choice for long-term treatment of hypertension during pregnancy by ESC, and the $\alpha / \beta$-blocker labetalol was considered to have efficacy comparable with methyldopa.

ACE inhibitors and angiotensin receptor blockers were contraindicated in pregnancy in all CPGs. Atenolol and other highly selective $\beta$-blocker drugs were not recommended for prolonged use in pregnancy as they have been associated with fetal growth restriction (SOMANZ and SOGC). Diuretics were not recommended for the treatment of hypertension (SOMANZ, SOGC, ACOG, ESC, NICE).

\section{Corticosteroids}

All CPGs recommended administration of corticosteroids for preterm pre-eclampsia. However, recommendations differed with regard to gestational age at initiation of therapy. Corticosteroids should be given in cases of preterm pre-eclampsia before 34 weeks (SOMANZ, NICE, QLD), $\leq 34+0$ (ACOG) or $34+6$ weeks (SOGC) gestation to reduce the risk of neonatal death, respiratory distress syndrome, cerebrovascular haemorrhage, necrotising enterocolitis, respiratory support and intensive care unit (ICU) admission. One CPG recommended consideration of antenatal corticosteroid therapy for women who present at $\leq 34+6$ weeks' gestation with gestational hypertension only if delivery is contemplated within the next 7 days (SOGC). One CPG did not recommend repeated dose of corticosteroids administered routinely (SOMANZ). Another CPG (SOGC) stated that a rescue dose of corticosteroids may be considered for women at $\leq 34+6$ weeks' gestation who remain at high risk of preterm delivery 7 days or more after an initial course of antenatal corticosteroids. Steroids may also be considered for women delivered by elective caesarean delivery at $\leq 38+6$ weeks' gestation to reduce respiratory morbidity (SOGC).

\section{Intravenous fluid maintenance}

Four of six CPGs described no benefit to intravenous fluid maintenance therapy and stated that it should be minimised in women with pre-eclampsia to avoid pulmonary oedema (SOGC, SOMANZ, ACOG, QLD). Administration of fluid at a rate greater than normal requirements should only be considered for women with severe pre-eclampsia immediately prior to parenteral hydralazine, regional anaesthesia or immediate delivery or as initial management in women with oliguria and a suspected or confirmed deficit in intravascular volume according to SOMANZ. One CPG recommended against fluid being administered to treat oliguria (SOGC). Neither dopamine nor furosemide were recommended by SOGC. Diuretics were considered inappropriate except in case of fluid overload or pulmonary oedema, according to QLD.

\section{Magnesium sulfate}

All six CPGS recommended magnesium sulfate for treatment of eclampsia. Four of six CPGs recommended it for severe pre-eclampsia (NICE, SOGC, QLD, ACOG). Guidelines stated that magnesium sulfate by infusion should be continued for $24 \mathrm{~h}$ after the last seizure (SOMANZ) or after delivery (QLD). Four CPGs recommended considering magnesium sulfate for prevention of eclampsia in women with mild pre-eclampsia (SOGC, 
SOMANZ, ESC, QLD). One CPG recommended against administration of magnesium sulfate with BP less than 160/110 (ACOG). SOMANZ and QLD advised IV diazepam $(2 \mathrm{mg} / \mathrm{min}$ to maximum of $10 \mathrm{mg}$ ) or clonazepam (1-2 $\mathrm{mg}$ over $2-5 \mathrm{~min})$ if the seizure is prolonged. Four guidelines stated that delivery of fetus should be done as soon as the woman's condition is stable, and close fetal monitoring should be done in the meantime. One CPG recommended that in women with pre-existing or gestational hypertension, magnesium sulfate should be considered for fetal neuroprotection in the setting of imminent preterm birth (within the next $24 \mathrm{~h}$ ) at $\leq 31$ +6 weeks (SOGC).

\section{Fetal surveillance}

Fetal surveillance recommendations varied among CPGs and differed in modality and frequency depending on the classification of HDP.

Early dating ultrasound (SOMANZ, QLD), ultrasound for fetal growth (SOMANZ, ACOG, SOGC, QLD), amniotic fluid volume (SOMANZ, SOGC, ACOG, QLD), umbilical artery Doppler flow (SOMANZ, SOGC, ACOG, QLD), and cardiotocography (SOMANZ, QLD) were all considered acceptable modalities for fetal surveillance.

\section{DISCUSSION}

Six CPGs covering the diagnostic approach and management of HDP were assessed using the AGREE II instrument. Two guidelines received the highest reviewer agreement ratings: one by the Society of Obstetricians and Gynaecologists of Canada ${ }^{21}$ and the other by the UK National Institute for Heath and Clinical Excellence. ${ }^{20}$ Both of these guidelines were thorough, well developed, organised and had clear recommendations.

All of the CPGs had similar criteria for hypertensive disorders of pregnancy. The main differences between guidelines were in the classification of severe hypertension and gestational hypertension. SBP requirements differed among guidelines when defining severe hypertension. Also, when trying to differentiate between gestational hypertension and chronic hypertension, the number of weeks that high BP continued after delivery differed. All guidelines defined chronic hypertension, severe hypertension, gestational hypertension, pre-eclampsia and superimposed pre-eclampsia. Some also included definitions for white coat hypertension, reverse white coat hypertension, HELLP syndrome and eclampsia.

The objectives and scope of the guidelines were very similar although two CPGs (SOMANZ, ESC) presented less detailed objectives. The overall objective of the CPGs was to prevent, diagnose and manage hypertensive disorders of pregnancy. Overall, the approach to management of these disorders varied the most when considering antihypertensive therapy. However, there was consensus among all CPGs that delivery is the definitive management for HDP and is followed by resolution of symptoms.
There was also general consensus that strict bed rest and intravenous fluid maintenance should not be recommended. The only general consensus on the use of antihypertensive medications was that antihypertensive medications should be started when BPs reach severe range. Specific antihypertensive medication recommendation varied among CPGs but included labetalol, nifedipine, hydralazine, diazoxide and methyldopa. Also, whether to continue or initiate antihypertensive medication in the mild to moderate hypertensive ranges differed among CPGs. All CPGs agreed that corticosteroids should be given for preterm pre-eclampsia, but the gestational date at which it should be given varied. All CPGs agreed that the treatment for eclampsia is magnesium sulfate. Some recommend that magnesium sulfate be given to women with mild pre-eclampsia to prevent eclampsia.

Some CPGs thoroughly developed recommendations for and against therapies for the prevention of HDP more than others. A consensus was made to recommend the use of low-dose aspirin in women with a history of a hypertensive disorder in a previous pregnancy to prevent it in the current pregnancy. Also, most guidelines recommended calcium supplementation in women with low serum calcium levels. All other prevention therapies either lacked sufficient evidence to make a recommendation or were recommended against.

A previous review of CPGs employed the minimum number of reviewers recommended by the AGREE Collaboration (ie, two) and consideration of a heterogeneous group of guidelines. ${ }^{28}$ The previous review reported inclusion criteria that allowed guidelines covering an individual hypertensive disorder, and guidelines covering all hypertensive disorders as a group, to be assessed alongside one another, making comparisons between dissimilar guidelines. Despite some disparity in reviewers' scores between these two reviews, the NICE guideline received the highest scores across all domains, while SOMANZ received the lowest. Our more rigorous approach of five reviewers of a more focused set of guidelines (ie, only those that relate to hypertensive disorders of pregnancy, overall) confirms that the NICE guideline has the most favourable profile and may serve as a model for future development of CPGs.

Strengths of the study include evaluation of each guidelines by five raters, comprehensive search strategy with the use of multiple databases and the use of a structured, validated tool. Limitations of the study include inclusion of only English language guidelines. This may result in the exclusion of guidelines designed for use in non-English speaking countries which may have been relevant. Differences between raters were not assessed. However, the larger number of raters in our study should improve reliability in the overall ranking of guidelines. The review focused on guidelines of broader scope which may have resulted in failure to identify guidelines which, though of narrow scope, may have been pertinent to recommendations. 


\section{CONCLUSION}

Current guidelines on the diagnosis, prevention and management of HDP make similar recommendations about treatment for prevention of HDP, severe BP, preterm pre-eclampsia and eclampsia. Despite these similarities, recommendations are still inconsistent across other topics potentially leading to inadequate guidance for physicians in care of patients.

Contributors ANB conceived of the idea for the manuscript. EG and $A B$ performed the literature search and obtained full text of the guidelines. $L A L B$, $A N B, E G$ and $A B$ performed independent ratings of each guideline. ANB, EG, $A M$ and $A B$ drafted the manuscript. $L A B$ and VG provided substantive review of the manuscript and contributed to the interpretation of the results. ANB had access to all data and is responsible for the content of the manuscript.

Funding This research received no specific grant from any funding agency in the public, commercial or not-for-profit sectors.

Competing interests None declared.

Provenance and peer review Not commissioned; externally peer reviewed.

Data sharing statement No additional data are available.

Open Access This is an Open Access article distributed in accordance with the Creative Commons Attribution Non Commercial (CC BY-NC 4.0) license, which permits others to distribute, remix, adapt, build upon this work noncommercially, and license their derivative works on different terms, provided the original work is properly cited and the use is non-commercial. See: http:// creativecommons.org/licenses/by-nc/4.0/

\section{REFERENCES}

1. Abalos E, et al. Preeclampsia, eclampsia and adverse maternal and perinatal outcomes: a secondary analysis of the World Health Organization Multicountry Survey on Maternal and Newborn Health. Bjog 2014;121:14-24.

2. Hutcheon JA, Lisonkova S, Joseph KS, Epidemiology of preeclampsia and the other hypertensive disorders of pregnancy. Best Pract Res Clin Obstet Gynaecol 2011;25:391-403.

3. Lo JO, Mission JF, Caughey AB, Hypertensive disease of pregnancy and maternal mortality. Curr Opin Obstet Gynecol 2013;25:124-32.

4. Dolea C, AbouZahr C, Global burden of hypertensive disorders of pregnancy in the year 2000 in Evidence and Information for Policy. 2003, World Health Organization: Geneva.

5. James PR, Nelson-Piercy C, Management of hypertension before, during, and after pregnancy. Heart 2004;90:6.

6. Xiong X, Demianczuk NN, Buekens $P$, Saunders LD, Association of preeclampsia with high birth weight for age. Am J Obstet Gynecol 2000;183:148-55.
7. Basso O, Ramussen S, Weinberg CR, et al. Trends in fetal and infant survival following preeclampsia. JAMA 2006;296:1357-1362

8. Friedman SA, Schiff E, Kao L, Sibai BM, Neonatal outcome after preterm delivery for preeclampsia. Am J Obstet Gynecol 1995;172:1785-8.

9. Vestergaard M, Basso O, Henriksen TB, et al. Preeclampsia and febrile convulsions. Arch Dis Child 2003;88:726-7.

10. Ferreira I, Peeters LL, Stehouwer CD, Preeclampsia and increased blood pressure in the offspring: meta-analysis and critical review of the evidence. J Hypertension 2009;27:1955-9.

11. Wu CS, Sun Y, Vestergaad M, et al. Preeclampsia and risk for epilepsy in offspring. Pediatrics 2008;122:1072-8.

12. Wu CS, Nohr EA, Bech BH, et al. Health of children born to mothers who had preeclampsia: a population-based cohort study. Am J obstet Gynecol 2009;201:269.e1-10.

13. Kajantie E, Eriksson JG, Osmond C, et al. Preeclampsia is associated with increased risk of stroke in the adult offspring: the Helsinki birth cohort study. Stroke 2009;40:1176-80.

14. Männistö $T$, Mendola $P$, Vääräsmäki $M$, et al. Elevated blood pressure in pregnancy and subsequent chronic disease risk. Circulation 2013;127:681-90.

15. Agency for Healthcare Research Quality. National Guidelines Clearinghouse Web Site. Accessed at wwww.guideline.gov on 19 May 2014.

16. Guidelines International Network Web site. Accessed at www.g-i-n net on 19 May 2014.

17. National Institute for Health for Health and Care Excellence Web site. Accessed at www.nice.org.uk on 19 May 2014.

18. Canadian Medical Association. CMA Infobase Web site. Accessed at www.cma.ca/clinicalresources.practiceguidelines on 19 May 2014.

19. Australian Government National Health and Medical Research Council. Clinical Practice Guidelines Portal Web site. Accessed at www.clinicalguidelines.gov.au on 19 May 2014.

20. Australian Government National Health and Medical Research Council. Clinical Practice Guidelines Search Web site. Accessed at www.nhmrc.gov.au/guidelines/publications on 19 May 2014.

21. Scottish Intercollegiate Guidelines Network Web site. Accessed at www.sign.ac.uk/guidelines/published/index.html on 19 May 2014.

22. New Zealand Ministry of Health. New Zealand Guidelines Group Web site. Accessed at www.health.govt.nz/about-ministry/ministryhealth-websites/new-zealand-guidelines-group on 19 May 2014.

23. Agency for Quality in Medicine. AQuMed Database Web site. Accessed at www.aezq.de/aezq/publications on 19 May 2014.

24. National Disease Management Guidelines Programme. German Disease Management Guidelines. Accessed at www. versorgungsleitlinien.de/english German Disease Management Guidelines.

25. British Columbia Ministry of Health. BCGuidelines Web site. Accessed at www.bcguidelines.ca/alphabetical on 19 May 2014.

26. AGREE Enterprise Web site. Accessed at www.agreetrust.org on 20 May 2014.

27. Roberts et al. ACOG's Task Force on Hypertension in Pregnancy. Hypertension in Pregnancy. Obstetrics \& Gynecology 122;2013:1122-31.

28. Gillon TE, Pels A, von Dadelszen $\mathrm{P}$, et al. Hypertensive disorders of pregnancy: a systemic review of international clinical practice guidelines. PLoS One 2014:9. 